\title{
Optimal combination of wage cuts and layoffs - the unexpected side effect of a performance-based payment system
}

\author{
Izumi Yokoyama* (D) and Takuya Obara
}

\section{*Correspondence:}

izumi.yokoyama@r.hit-u.ac.jp Graduate School of Economics, Hitotsubashi University, 2-1 Naka, Kunitachi, 186-8601 Tokyo, Japan

\begin{abstract}
This study analyzes the trade-off relationship between layoffs and wage cuts. If the introduction of a performance-based payment system stimulates workers' pecuniarymotivated minds, their morale can be damaged more severely by wage cuts than prior to the introduction thereof. Utilizing this idea, we demonstrate theoretically that the more heavily wages are based on performance, the more firms, fearing that workers' morale will be damaged by wage cuts, try to avoid wage cuts and instead prefer layoffs. Next, we show empirically the trend whereby firms with performance-based payment systems are unlikely to implement wage cuts. Given this first-stage regression, the status of a performance-based payment system, based on the firm's past decision and assured to be exogenous, is employed as an instrumental variable (IV) for wage cuts in a layoff regression model to overcome simultaneous bias. In the second-stage regression, the IV estimates for the impact of wage cuts on layoffs are significantly negative: if a firm implements wage cuts, it will reduce the probability of layoffs by 0.172 . This supports the theoretical implication that implementing wage cuts can be a potential device for reducing layoffs. These results may imply an unexpected side effect of the increasing use of performance-based payment systems: as such systems become more widespread, layoffs will increase because firms will become less likely to impose wage cuts, thus potentially resulting in high unemployment.
\end{abstract}

JEL Classification: J30, J33, J63

Keywords: Layoff, Wage cut, Morale, Performance-based payment system

\section{Introduction}

If firms face financial crisis during a recession and this situation continues, there is a possibility of those firms going bankrupt. To avoid this worst-case scenario, some firms may consider reconstructing their businesses before it is too late. Indeed, there have been periods of recession in Japan in which many firms have tried to reconstruct their businesses (e.g., the financial and real estate bubble at the end of the 1980s, the Asian currency crisis in 1997, the IT bubble in the early 2000s, and the global financial crisis in 2008). During financial crises, if there is no surplus money to invest in reconstruction, firms need to collect funds by implementing layoffs and/or wage cuts.

According to Bewley's (1999) findings, when firms are forced to decide between layoffs and wage cuts, there is a tendency to adopt the former. What, then, is the mechanism whereby firms are reluctant to cut wages and tend to implement layoffs? ${ }^{1}$

(c) The Author(s). 2017 Open Access This article is distributed under the terms of the Creative Commons Attribution 4.0 International License (http://creativecommons.org/licenses/by/4.0/), which permits unrestricted use, distribution, and reproduction in any medium, provided you give appropriate credit to the original author(s) and the source, provide a link to the Creative Commons license, and indicate if changes were made. 
Bewley (1999) implemented commendable field research and provided a clue to the cause of nominal wage rigidity. According to Bewley (1999), the key reason for a firm's reluctance to cut wages is the belief that nominal wage cuts damage worker morale. Many studies have since appeared in support of Bewley's finding (Gneezy and List 2006; HennigSchmidt et al. 2010; Kawaguchi and Ohtake 2007; Kube et al. 2013).

For example, Kube et al. (2013) conducted field experiments and found evidence that is consistent with Bewley's (1999) finding that workers' morale does not increase with a wage increase, although it can be damaged by pay reductions. Hennig-Schmidt et al. (2010) also showed that it is not necessarily that workers' efforts increase in response to an increase in their wages. In a field experiment, Gneezy and List (2006) found that the positive effects of wage increase on productivity dwindle over time. Using an employeremployee survey conducted in Japan, Kawaguchi and Ohtake (2007) showed that workers are demoralized by nominal compensation cuts, even during times of deflation. Their results support the morale theory of wage rigidity, which is again consistent with Bewley's (1999) finding.

Thus, it should not be an overstatement to say that workers' morale is a key factor in considering the effect of wage cuts. In this study, we investigate the mechanism whereby firms are reluctant to cut wages and tend to implement layoffs by clearly introducing a parameter that represents the magnitude of decline in morale caused by wage cuts. To empirically explore this mechanism, we require a proxy variable for the parameter, and as a candidate for the proxy, we utilize information on the performance-based payment system for each firm.

As performance-based pay has become widespread in many countries since the 1990s, many researchers have explored the effects thereof on workers' motivation and morale. It is well known that one of the positive aspects of performance-based pay systems is that they incentivize workers to work hard, but it has also been shown that such systems have negative effects on workers. Among these negative effects, the most famous are called "crowding out" effects: According to Frey (1997) and Frey and Jegen (2001), external intervention via monetary incentives such as the introduction of a performance-based pay system may undermine workers' intrinsic motivation. This "crowding out" occurs when the negative effect on intrinsic motivation of offering a monetary reward outweighs the positive extrinsic motivation. This negative effect runs counter to the traditional predictions of economic theory; however, what is very understandable is the fact that the introduction of a performance-based payment system will increase the weight of motivation that comes from the amount of money paid. It is then easy to imagine that with their pecuniary-motivated mindset, workers' morale can be damaged more by wage cuts in a performance-based payment system, and the more pay is based on performance, the more severely workers' morale can be damaged by wage cuts.

Utilizing this idea, in the theoretical section of our study, we use a wage piece rate, i.e., a reward paid for each unit of productivity, as the parameter that represents the degree to which pay is based on performance. Then, in the empirical section, we use information on whether the firm is using a performance-based payment system as the proxy for the parameter.

We first construct a theoretical model to illustrate the mechanism whereby firms become more reluctant to cut wages when the expected reduction in morale caused by such wage cuts is greater, and, as a result, tend to implement layoffs. 
The main results obtained from the theoretical model are as follows: (i) the more sensitive workers' morale is to wage cuts, the more reluctant firms become to cut wages, and in such cases, firms prefer layoffs to wage cuts. (ii) If the wage piece rate, which represents the degree to which pay is based on performance, exceeds a certain threshold, firms do not implement wage cuts and instead collect funds solely by implementing layoffs.

While empirically demonstrating the trade-off between wage cuts and layoffs is an important issue, estimating the relationship credibly is difficult due to simultaneity. Thus, by employing the status of a performance-based payment system, based on the firm's past decision and assured to be exogenous, as the instrumental variable (IV) for wage cuts, we estimate the impact of wage cuts on layoffs. The result of the first-stage regression is consistent with the theoretical prediction: firms that adopt a performance-based payment system are less likely to cut wages. Confirming the sufficient correlation of the IV stated above and wage cuts, the IV method of the second stage is performed. In the second stage, we regress layoffs on wage cuts using the IV, and the coefficient on wage cuts then becomes significantly negative. More concretely, using the most preferable specification, if a firm implements wage cuts, it will reduce the probability of layoff by 0.172 . In other words, this may suggest that wage cuts and layoffs are in a mutually alternative relationship, and the result of the estimated causal relationship suggests that wage cuts function as an effective measure to avert layoffs. In this study, we obtain a result that is exactly consistent with the argument of the existing studies on downward wage rigidity; that is, if wages are not decreased during a recession, it may prevent new workers from being hired (Akerlof 1982; Akerlof and Yellen 1988, 1990; Azariadis 1975; Baily 1974; Gordon 1974; Lindbeck and Snower 1988; Shapiro and Stiglitz 1984).

To sum up, based on the efficiency wage hypothesis, even if a firm tries to increase employee incentives by employing a performance-based payment system, as this unintentionally acts as a device for stimulating workers' pecuniary-motivated minds, their morale can be damaged more severely by wage cuts than prior to the introduction thereof. As a result, the firm may end up shying away from imposing wage cuts. In such cases, where wage cuts are unlikely to be imposed, layoffs are likely.

This paper is organized as follows. Section 2 describes the framework of the basic model. Section 3 presents an empirical strategy to test the implications of the theoretical model. Section 4 provides a brief description of the data, and Section 5 discusses the results from the empirical analysis. Finally, Section 6 presents the conclusion.

\section{Basic model}

Suppose that a firm faces financial crisis during a recession and if this continues, there is a possibility that the firm will go bankrupt. To avoid this worst-case scenario, the firm may consider reconstructing its business before it is too late. Let us assume that the amount of funds necessary for reconstruction is $Y$. Here, it is also assumed that during a financial crisis, there is no extra money to invest in reconstruction, and thus, the firm needs to collect money by implementing layoffs and/or wage cuts, $d$, per worker. Before layoffs are conducted, the total number of workers is $N$. 
We assume that wage level is determined based on two components, namely, a fixed pay component and a performance-based pay component. Therefore, wages are expressed as follows:

$$
w(q)=\underline{w}+b q
$$

where $\underline{w}$ represents fixed pay and $b$ represents the "piece rate" paid for each unit of productivity, $q$, which is distributed by $F(q)$ that is the productivity distribution function, with a density function $f(q)>0$ for any $q \in[\underline{q}, \bar{q}]$. Thus, $b q$ represents performance-based pay. As a result, $w(q)$ becomes the total wages, which is an increasing function for $q$.

Before adopting wage cuts, the original wage level is given by $w(q)$, and the wage is adjusted by the amount of the wage cut, $d .^{2}$ We also assume that a firm implements wage cuts fairly, meaning that the same amount, $d$, is applied regardless of productivity. When a layoff is conducted, it is accompanied by a layoff cost per worker of $c_{L}$, which captures the severance allowance or cost to search employees who match the employer's preferences.

Although a wage cut can only reduce wage cost, when a layoff is implemented, it is considered that the fixed costs of employment $\left(c_{H}\right)$, such as benefits other than wages, including labor space and resources, can also be reduced. We also assume that when wage cuts are implemented, no transaction costs such as those for negotiation are incurred.

For firms, the effect that wage cuts have on workers' productivity is considered unknown, and when wage cuts are introduced, a determination is made for wages after predicting the effect on productivity in advance. At that time, the magnitude of the impact resulting from the same amount of wage cuts is considered to be common for all workers, and for a one-dollar wage cut, a decline in worker productivity of $\alpha>0$ is expected. ${ }^{3}$

As stated in the introduction, with their pecuniary-motivated minds, workers' morale can be damaged more by wage cuts under the performance-based payment system, and the more pay is based on performance, the more severely workers' morale can be damaged by wage cuts. Utilizing this idea, we use a wage piece rate, i.e., a reward paid for each unit of productivity, as the parameter that represents the degree to which pay is based on performance. Thus, $\alpha$ is a strictly increasing function of $b$, i.e., the degree to which pay is based on performance. It is interpreted that wages and morale are more strongly associated under the performance-based pay system. Therefore, firms can simply estimate that following a $d$ dollar wage cut for workers with an original productivity of $q$, the productivity will be $q-\alpha(b) d$. As a result, the wage level after conducting a wage cut is rewritten as follows:

$$
\hat{w}(q)=\underline{w}-d+b(q-\alpha(b) d)=w(q)-d-b \alpha(b) d
$$

Let $\hat{w}(q)$ denotes the modified wage level, and we naturally assume that $\hat{w}(q)$ is positive. We can decompose the effect of wage cuts into two terms: direct effect and indirect effect. The second term in Eq. 2, $d$, is the direct effect, which expresses the direct decrease in wage level due to wage cuts $(d)$. On the other hand, the third term in Eq. 2, $b \alpha(b) d$, is the indirect effect because this is the indirect decrease in wage level through the decline in performance owing to wage cuts. As a recession is considered in this case, it is assumed that no spontaneous turnover of workers due to wage cuts will occur.

In contrast, what the firm can save by laying off one worker before cutting wages is the sum of the total wage $(w(q))$ and other fixed costs of employment $\left(c_{H}\right)$, that is, $w(q)+$ 
$c_{H}$. The number of workers subject to layoffs with a productivity below $\hat{q}$ is represented by $N F(\hat{q})$. As a result, if a firm carries out layoffs, it can save $N \int_{\underline{q}}^{\hat{q}}\left(w(q)+c_{H}\right) f(q) d q .{ }^{4}$ Furthermore, by performing the layoffs, the total number of workers will be $N(1-F(\hat{q}))$ persons. Therefore, by performing a wage cut of $d$ yen per worker, it is possible to procure funds of $N(1-F(\hat{q})) d$ yen overall. In addition, wage cuts affect performance, which leads to a decrease in performance-based pay. As a result, a firm can save the payment $b \alpha(b) d$ per worker, for a total of $N(1-F(\hat{q})) b \alpha(b) d$. To sum up, the firm can save the amount of $(w(q)-\hat{w}(q)) N(1-F(\hat{q}))$ in total. In this way, firms can secure necessary funds $(Y)$. When this is expressed formulaically, it results in Eq. 3:

$$
Y=N \int_{\underline{q}}^{\hat{q}}\left(w(q)+c_{H}\right) f(q) d q+(w(q)-\hat{w}(q)) N(1-F(\hat{q}))
$$

However, if a firm implements layoffs or wage cuts, a variety of costs occur. The costs incurred by layoffs include not only layoff costs $\left(c_{L}\right)$ but also production decreases caused by the decrease in the number of workers. On the other hand, if a firm implements a wage cut of $d$ yen, the productivity of workers who are not laid off will decline by $\alpha(b) d$ per worker. Thus, the total cost caused by a wage cut is equal to $N(1-F(\hat{q})) \alpha(b) d$ because the number of workers is $N(1-F(\hat{q}))$ after implementing layoffs. Hence, we can express each cost as follows:

$$
\begin{aligned}
\text { Layoff Cost } & =N \int_{\underline{q}}^{\hat{q}} q f(q) d q+N F(\hat{q}) c_{L} \\
\text { Wage-Cut Cost } & =N(1-F(\hat{q})) \alpha(b) d
\end{aligned}
$$

In this situation, a firm chooses $\hat{q}$ and $d$ to minimize the sum of the layoff cost and wage-cut cost subject to Eq. 3 to collect funds $Y$. Therefore, we can set the following optimization problem.

$$
\begin{array}{r}
\min _{\hat{q} \geq \underline{q}, d \geq 0} N \int_{\underline{q}}^{\hat{q}} q f(q) d q+N F(\hat{q}) c_{L}+N(1-F(\hat{q})) \alpha(b) d \\
\text { s.t. } Y=N \int_{\underline{q}}^{\hat{q}}\left(w(q)+c_{H}\right) f(q) d q+(w(q)-\hat{w}(q)) N(1-F(\hat{q}))
\end{array}
$$

We can then write the Lagrangian for this optimization problem as

$$
\begin{aligned}
\mathcal{L}= & N \int_{\underline{q}}^{\hat{q}} q f(q) d q+N F(\hat{q}) c_{L}+N(1-F(\hat{q})) \alpha(b) d \\
& +\lambda\left(Y-N \int_{\underline{q}}^{\hat{q}}\left(w(q)+c_{H}\right) f(q) d q-(w(q)-\hat{w}(q)) N(1-F(\hat{q}))\right)
\end{aligned}
$$

where $\lambda$ is the Lagrange multiplier on the constraint (3). The first-order conditions with respect to $d, \hat{q}$, and $\lambda$ are given by

$$
\begin{aligned}
\frac{\partial \mathcal{L}}{\partial d}= & N \alpha(b)(1-F(\hat{q}))-\lambda N(1-F(\hat{q}))-\lambda N(1-F(\hat{q})) b \alpha(b)=0 \\
\frac{\partial \mathcal{L}}{\partial \hat{q}}= & N \hat{q} f(\hat{q})+N c_{L} f(\hat{q})-N \alpha(b) d f(\hat{q}) \\
& -\lambda\left(\left(w(\hat{q})+c_{H}\right) N f(\hat{q})-N f(\hat{q}) d-N f(\hat{q}) b \alpha(b) d\right)=0 \\
\frac{\partial \mathcal{L}}{\partial \lambda}= & Y-N \int_{\underline{q}}^{\hat{q}}\left(w(q)+c_{H}\right) f(q) d q-N(1-F(\hat{q})) d-N(1-F(\hat{q})) b \alpha(b) d=0
\end{aligned}
$$


Before beginning to examine the properties of optimal solution, we assume the following condition:

\section{Assumption 1}

$$
Y<N \int_{\underline{q}}^{\bar{q}}\left(w(q)+c_{H}\right) f(q) d q
$$

This assumption means that the firm does not have to lay off all workers to collect necessary funds, $Y$. In other words, the amount of funds needed, $Y$, is not of such a large scale that the firm has to lay off all workers. If this assumption was violated, the firm could not remain in business because the financial crisis would be especially serious.

Note that if this assumption holds, $\frac{\partial \mathcal{L}}{\partial \lambda}$ in Eq. 10 will never equal zero but will always take a negative value, which means that this first-order condition will never be satisfied. This is equivalent to saying that the optimal level of $\hat{q}$ cannot be $\bar{q}$ because the cost-minimizing firm's objective is to collect the necessary amount of funds, $Y$, at the lowest cost, and thus, no cost-minimizing firm will fire all workers to collect more money than is necessary.

From Eq. 8 and $F(\hat{q})<1$, we can obtain

$$
\lambda=\frac{\alpha(b)}{1+b \alpha(b)}
$$

By substituting Eq. 12 into Eq. 9, we have

$$
\hat{q}=\frac{\alpha(b)}{1+b \alpha(b)}\left(w(\hat{q})+c_{H}\right)-c_{L}
$$

Moreover, substituting Eq. 13 into Eq. 10 yields

$$
d=\frac{Y-N \int_{\underline{q}}^{\hat{q}}\left(w(q)+c_{H}\right) f(q) d q}{(1+b \alpha(b)) N(1-F(\hat{q}))}
$$

Equations 13 and 14 comprise the optimal cutoff point in terms of layoffs and the optimal level of wage cuts, respectively. From these results, the following can be said:

\section{Proposition 1}

(1) Suppose that the first derivative of $\alpha$ with respect to the piece rate (b), denoted by $\alpha^{\prime}(b)$, is sufficiently large. Then, as the degree of performance-based pay (b) rises, the level of wage cut declines and the level of cut-off point for layoffs rises.

(2) The higher the fixed wage level (w) or fixed costs of employment $\left(c_{H}\right)$, the lower the level of a wage cut and the higher the level of the cutoff point for layoff. Furthermore, the higher a layoff cost $\left(c_{L}\right)$, the higher the level of a wage cut and the lower the level of the cutoff point for layoff.

Proof

Prooffor Proposition 1.1

By differentiating Eq. 13 with respect to $b$, we obtain

$$
\frac{\partial \hat{q}}{\partial b}=\frac{\alpha(b)}{1+b \alpha(b)}\left[b \frac{\partial \hat{q}}{\partial b}+\hat{q}\right]+\left(w(\hat{q})+c_{H}\right)\left[\frac{\alpha^{\prime}(b)}{1+b \alpha(b)}-\frac{\alpha(b)\left(\alpha(b)+b \alpha^{\prime}(b)\right)}{(1+b \alpha(b))^{2}}\right]
$$

Rearranging this equation, we can procure the following: 


$$
\frac{\partial \hat{q}}{\partial b}=\alpha(b)\left[\frac{w(\hat{q})+c_{H}}{1+b \alpha(b)} \frac{\alpha^{\prime}(b)}{\alpha(b)}-c_{L}\right]
$$

Note that according to Bewley (1999), the key reason for a firm's reluctance to cut wages is the belief that nominal wage cuts damage worker morale. This finding is nothing but a proof that $\alpha(b)$, i.e., firms' belief about the magnitude of a decline in worker productivity in response to a one-dollar wage cut, is not small. Given this situation, $\alpha^{\prime}(b)$ should be large enough for Eq. 16 to be positive.

Similarly, by differentiating Eq. 14 with respect to $b$, we have

$$
\begin{array}{r}
\frac{\partial d}{\partial b}=\frac{1}{(1+b \alpha(b))(1-F(\hat{q}))}\left[\frac{\partial \hat{q}}{\partial b} f(\hat{q})\right. \\
\left\{d(1+b \alpha(b))-\left(w(\hat{q})+c_{H}\right)\right\} \\
\left.-d(1-F(\hat{q}))\left(\alpha(b)+b \alpha^{\prime}(b)\right)\right]
\end{array}
$$

From the definition of $\hat{w}(q)$, as well as Eq. 2, the modified wage can be written as $\hat{w}(q)=$ $w(q)-d-b \alpha(b) d$. Then, by substituting this into Eq. 17, we can rewrite $\frac{\partial d}{\partial b}$ as follows:

$$
\frac{\partial d}{\partial b}=\frac{1}{(1+b \alpha(b))(1-F(\hat{q}))}\left[\frac{\partial \hat{q}}{\partial b} f(\hat{q})\left(-\hat{w}(\hat{q})-c_{H}\right)-d(1-F(\hat{q}))\left(\alpha(b)+b \alpha^{\prime}(b)\right)\right]
$$

Therefore, from the assumption that $\hat{w}(q)$ is positive for any $q$, we can conclude that the sign of $\frac{\partial d}{\partial b}$ is negative as long as $\frac{\partial \hat{q}}{\partial b}$ is positive.

Prooffor Proposition 1.2

Similarly, we can prove Proposition 1.2 as follows:

$$
\begin{aligned}
\frac{\partial \hat{q}}{\partial \underline{w}}=\alpha(b)>0 & \frac{\partial(\hat{q})}{\frac{\partial \underline{w}}{=}}-\frac{f(\hat{q})}{(1+b \alpha(b))(1-F(\hat{q}))} \\
& +\frac{\partial \hat{q}}{(1+b \alpha(b))(1-F(\hat{q}))} \frac{\partial \underline{w}}{\partial \hat{q}}=\left(d(1+b \alpha(b))-\left(w(\hat{q})+c_{H}\right)\right)<0 \\
\frac{\partial c_{H}}{\partial d}= & -\frac{F(\hat{q})}{(1+b \alpha(b))(1-F(\hat{q}))} \\
& +\frac{f(\hat{q})}{(1+b \alpha(b))(1-F(\hat{q}))} \frac{\partial \hat{q}}{\partial c_{H}}\left(d(1+b \alpha(b))-\left(w(\hat{q})+c_{H}\right)\right)<0 \\
\frac{\partial \hat{q}}{\partial c_{L}}= & -(1+b \alpha(b))<0 \\
\frac{\partial d}{\partial c_{L}}= & \frac{f(\hat{q})}{(1+b \alpha(b))(1-F(\hat{q})} \frac{\partial \hat{q}}{\partial c_{L}}\left(d(1+b \alpha(b))-\left(w(\hat{q})+c_{H}\right)\right)>0
\end{aligned}
$$

These results are intuitive. First, when $\alpha^{\prime}(b)$ is sufficiently large, workers' morale is significantly affected by the wage piece rate and, hence, a performance-based payment system $^{5}$. In this case, the more pay is based on performance, the more severely workers' morale can be damaged by wage cuts, and thus, firms tend to implement layoffs rather 
than wage cuts. Second, the increase in the level of the original wages $(w)$ or fixed costs of employment $\left(c_{H}\right)$, such as benefits other than wages, implies that when the firm implements layoffs, it can save more funds. Therefore, these factors can also be an incentive for the firm to implement layoffs rather than wage cuts. Inversely, the higher the layoff cost per worker $\left(c_{L}\right)$, the less the incentive for the firm to implement layoffs. In this way, from Proposition 1, we have obtained the fact that there is a trade-off relationship between layoffs and wage cuts.

Herein, we theoretically investigate the reasons why firms tend to adopt layoffs rather than wage cuts; that is, almost no firms simultaneously implemented both layoffs and wage cuts as shown in the results of Bewley's (1999) research.

If a firm does not implement wage cuts and collects funds $Y$ by layoffs only, the following equation holds from Eq. 10:

$$
N \int_{\underline{q}}^{\hat{q}}\left(w(q)+c_{H}\right) f(q) d q=Y
$$

In contrast, if $N \int_{\underline{q}}^{\hat{q}}\left(w(q)+c_{H}\right) f(q) d q<Y$ holds, the firm simultaneously implements both layoffs and wage cuts. From Proposition 1, we can say that Eq. 25 is likely to hold when

- Piece rate, $b$, is high, which means wage cuts greatly demoralize workers.

- Layoff costs, $c_{L}$, are low (e.g., the amount of retirement benefits is low).

- The fixed costs of employment, $c_{H}$, that a firm can save by implementing layoffs are large.

- The amount of the total wage, $w$, is high.

Next, we will focus on the effect of the piece rate, $b$, on a firm's choice between layoffs or wage cuts. As Bewley (1999) observed in his interview studies, the main reason a firm avoids wage cuts is that they damage morale. If a firm conducts wage cuts, it may demoralize workers, and the damage to morale can be larger when the piece rate is higher. Hence, the level of $b$ greatly affects a firm's decision to implement layoffs or wage cuts. Now, we define $\bar{b}$ as the value that satisfies Eq. 25. We can express this as an equation

$$
N \int_{\underline{q}}^{\hat{q}(\bar{b})}\left(w(q)+c_{H}\right) f(q) d q=Y
$$

This means that, since a firm whose piece rate is $\bar{b}$ expects that a decline in worker productivity by conducting wage cuts is most sensitive, it conducts layoffs only. From the

fact that $\bar{b}$ is a threshold, if the firm's piece rate is higher than $\bar{b}$, it keeps implementing layoffs only, while if a firm's piece rate is lower than $\bar{b}$, it simultaneously implements both layoffs and wage cuts. Hence, the following proposition summarizes these results.

\section{Proposition 2}

(1) If the piece rate meets a certain threshold ( $\bar{b}$ ) or higher (i.e., if $b \geq \bar{b}$ holds), a firm will implement layoffs only.

(2) Otherwise (i.e., if $\underline{b}<b<\bar{b}$ holds), a firm will simultaneously implement both layoffs and wage cuts.

where $\underline{b}$ is the minimum level of $b$, with which a firm implements wage cuts only. 
In Proposition 2, we focus only on the relationship between the piece rate and the firm's choice between wage cuts and layoffs. We can theoretically confirm that the firm collects funds by implementing only layoffs if the piece rate $(b)$ is sufficiently large. Therefore, in a situation where wage cuts damage the worker's productivity, the higher the piece rate $b$, the more firms try to avoid wage cuts and prefer layoffs.

\section{Empirical model}

Given the theoretical implication, we will consider the following model in the empirical part to examine the trade-off between layoffs and wage cuts using data

$$
\text { Layoff }_{i t}=\alpha_{0}+\alpha_{1} \text { WageCut }_{i t}+X_{i t} \gamma+u_{i t}
$$

where Layoff $i t$ is an indicator function that equals one if firm $i$ has implemented layoffs in year $t$ and WageCut ${ }_{i t}$ is an indicator function that equals one if the firm imposed wage cuts in order to prevent layoffs in year $t$. Thus, given the trade-off relationship confirmed in the theoretical part, $\alpha_{1}$ is expected to be negative when a firm has to decide between layoffs and wage cuts. However, as layoffs and wage cuts are determined at the same time, Eq. 27 has the problem of simultaneity; thus, the coefficients would suffer from a simultaneous bias. For example, in a regular probit model where the simultaneous bias is not considered, as wage cuts and layoffs are likely to occur at the same firm during economic distress, both can be thought to have a positive correlation, which leads to an upward bias in $\hat{\alpha}_{1}$. However, what we want to capture is the causal relationship that represents whether implementing wage cuts contributes to avoiding layoffs. To do this, we need an appropriate instrument variable for $\mathrm{WageCut}_{i t}$.

As a factor that influences the firm's behavior toward wage cuts but has no effect on layoffs, the answer to the question "do you currently employ a performance-based payment system?" can be a candidate as an instrumental variable for the wage cut dummy. If a performance-based payment system stimulates workers' pecuniary-motivated minds, wage cuts could damage worker morale more after introduction of this system than before. Thus, a firm that uses a performance-based payment system would more likely opt for layoffs than wage cuts.

In the first place, the status of a performance-based payment system could be considered a good candidate as an IV for wage cuts only if the two variables are sufficiently correlated. To examine if there is enough correlation between the two, we will first implement the following first-stage regression:

$$
\text { WageCut }_{i t}=\beta_{0}+\beta_{1} \text { PerformancePay }_{i t}+X_{i t} \gamma+\epsilon_{i t}
$$

where PerformancePay ${ }_{i t}$ is an indicator function that equals to one if firm $i$ is employing a performance-payment system in year $t$. The coefficient $\beta_{1}$ is expected to be significantly negative. In other words, it raises the hypothesis that the more a firm uses a performance-based payment system, the greater is the expected decline in employee morale as a result of wage cuts. If, after first examining this hypothesis, the use or nonuse of a performance-based payment system is found to affect the imposition of wage cuts statistically significantly, and if the error term, $u_{i t}$, in Eq. 27 is uncorrelated with PerformancePay $_{i t}$, this variable can potentially be an instrumental variable for WageCut ${ }_{i t}$.

If the simultaneous bias is removed by the IV method in Eq. 27, it can be expected that $\hat{\alpha}_{1}$, which is significantly negative, will be obtained. 


\section{Data}

The data used in this paper are from the "Survey on Business Restructuring and Employment, 2002" by the Japan Institute for Labor Policy and Training (known then as the "Japan Institute of Labor"). This survey was conducted in response to the economic slump that commenced in the late 1990s, as well as the intensification of competition between firms both domestically and overseas, with the aim of reviewing business development, resource allocation, etc. and clarifying how business restructuring was progressing at the corporate level. The survey included a firm-level survey targeted at firms and an employee (personal) survey targeted at persons re-employed by those firms; however, as the decision-maker in our theoretical model is the firm, only the corporate survey was used in this study. The firm-level survey targeted all firms with over 300 employees and, after the performance of a random sampling, achieved a collection rate of $15.6 \%$, with a total of 1683 firms.

This firm-level survey is suitable for the examination of the theoretical model presented in the previous chapters because it asked (1) whether any domestic employees had been subject to layoffs in the previous three years, (2) whether firms that had laid off employees had imposed wage cuts in order to prevent layoffs, and (3) to what extent a performancebased payment system had been adopted as a means to provide financial incentives. In terms of surveys that shed light on such sensitive matters on the employer's side, it is comparable in scale and content to Bewley's survey conducted in the USA.

Table 1 summarizes the descriptive statistics of this study. As predicted, the probability of wage cuts is lower for firms using a performance-based pay system. Thus, under such systems, firms become more reluctant to cut wages, worrying about the reduction

Table 1 Descriptive statistics

\begin{tabular}{|c|c|c|c|}
\hline & $(1)$ & $(2)$ & (3) \\
\hline & All & Performance pay = 1 & Performance pay $=0$ \\
\hline \multirow[t]{2}{*}{ Firm age } & 60.330 & 60.415 & 60.292 \\
\hline & $(37.644)$ & $(41.392)$ & $(35.866)$ \\
\hline \multirow[t]{2}{*}{ Capital size (million yen) } & 5746.805 & 4241.802 & 6418.290 \\
\hline & $(55,183.413)$ & $(14,671.411)$ & $(65,633.987)$ \\
\hline Layoff $=1$ & 0.036 & 0.037 & 0.035 \\
\hline Performance pay = 1 & 0.309 & 1.000 & 0.000 \\
\hline Wage cut $=1$ & 0.011 & 0.007 & 0.013 \\
\hline Limitation for voluntary retirement $=1$ & 0.012 & 0.017 & 0.010 \\
\hline \multicolumn{4}{|l|}{ Reason for downsizing dummies } \\
\hline $\begin{array}{l}\text { To cope with present critical management } \\
\text { adversity }\end{array}$ & 0.185 & 0.193 & 0.181 \\
\hline $\begin{array}{l}\text { To cope with critical management adversity } \\
\text { expected in the future }\end{array}$ & 0.183 & 0.180 & 0.184 \\
\hline $\begin{array}{l}\text { To cope with a present, temporary profit } \\
\text { reduction }\end{array}$ & 0.087 & 0.091 & 0.085 \\
\hline $\begin{array}{l}\text { To improve earnings by focusing on the } \\
\text { company's specialty }\end{array}$ & 0.043 & 0.050 & 0.040 \\
\hline No response & 0.013 & 0.024 & 0.008 \\
\hline Observations & 1491 & 460 & 1031 \\
\hline
\end{tabular}

Note: Standard deviations are in parentheses. One question concerns the application criteria and limitations regarding eligibility for voluntary retirement and the early retirement incentive plan. "Limitation for Voluntary Retirement" takes the value of 1 if the firm circled at least one of the following categories: age, tenure, position, job type, and department. For firms that had not yet laid off workers, the question about the reason for downsizing asks about the main possible reason for the potential downsizing 
in worker morale. At the same time, the probability of implementing layoffs is higher for firms using the performance-based pay system. For firms that had not yet laid off workers, the question on downsizing asks about the main possible reason for the potential downsizing. Since all firms in the sample actually answered this question about the reasons for (potential) downsizing, these firms are likely to be facing some necessity to downsize now or in the future or can imagine why they might downsize in a future crisis. Note that they answered the questions regardless of whether the firm had already implemented layoffs.

\section{Empirical results}

In the explanatory variables, we included the capital size, firm age, limitation for voluntary retirement, and reason for downsizing dummies. ${ }^{6}$

Through the first-stage regression, we will verify the hypothesis that, within a firm that adopts the performance-based payment system, wage cuts are less likely to be implemented. Here, the dummy variable representing whether or not wage cuts are implemented is regressed on a dummy variable representing whether or not the performancebased payment system is adopted. If the hypothesis is supported, then the coefficient of the performance-based payment system dummy variable should be significantly negative.

The result of this first stage regression is shown in Table 2. As predicted, the coefficients of the performance-based payment system dummy are significantly negative. This suggests that the dummy variable of the performance-based payment system may be

Table 2 First-stage regression (probit)

\begin{tabular}{|c|c|c|}
\hline Dependent variable: wage cut $=1$ & $(1)$ & $(2)$ \\
\hline \multirow{2}{*}{ Performance pay = 1} & -0.0069 & -0.008 \\
\hline & $(0.0036)$ & $(0.004)$ \\
\hline \multirow[t]{2}{*}{ In(capital size (million yen))/100 } & 0.037 & 0.012 \\
\hline & $(0.056)$ & $(0.058)$ \\
\hline \multirow[t]{2}{*}{ Firm Age/1000 } & 0.029 & 0.031 \\
\hline & $(0.051)$ & $(0.050)$ \\
\hline \multirow[t]{2}{*}{ Limitation for voluntary retirement } & - & 0.019 \\
\hline & & $(0.016)$ \\
\hline \multicolumn{3}{|l|}{ Reason for downsizing dummies } \\
\hline \multirow[t]{2}{*}{ To cope with critical management adversity expected in the future } & - & 0.021 \\
\hline & & $(0.014)$ \\
\hline \multirow[t]{2}{*}{ To cope with a present, temporary profit reduction } & - & 0.006 \\
\hline & & $(0.012)$ \\
\hline \multirow[t]{2}{*}{ To improve earnings by focusing on the company's specialty } & - & -0.003 \\
\hline & & $(0.005)$ \\
\hline \multirow[t]{2}{*}{ No response } & - & 0.004 \\
\hline & & $(0.003)$ \\
\hline Foundation year dummies & Yes & Yes \\
\hline Pseudo- $R^{2}$ & 0.024 & 0.048 \\
\hline$N$ & 1491 & 1491 \\
\hline \multicolumn{3}{|c|}{$\begin{array}{l}\text { Note: Standard errors clustered at an industry level are reported in parentheses. Marginal effects evaluated at the mean of the } \\
\text { covariates are reported. One question concerns the application criteria for and limitations on eligibility for voluntary retirement } \\
\text { and the early retirement incentive plan. "Limitation for Voluntary Retirement" takes the value of } 1 \text { if the firm circled at least one of } \\
\text { the following categories: age, tenure, position, job type, and department. The reference group for the downsizing reason } \\
\text { dummies is "To Cope with Present Critical Management Adversity." For firms that had not yet laid off workers, the question on } \\
\text { downsizing asks about the main possible reason for the potential downsizing }\end{array}$} \\
\hline
\end{tabular}


an appropriate candidate as the IV of the wage-cut dummy variable. This result supports Proposition 2, which states that if the piece rate $(b)$ is sufficiently high, layoffs are preferred to wage cuts.

The probit and IV-probit (hereafter, IV) results are shown in Table 3. As predicted, the coefficient of the wage-cut dummy variable is positive in the probit obtained without the use of the instrumental variable method. In contrast, the IV estimate of the wage-cut coefficient, using the performance-based payment system dummy variable as an IV, was significantly negative. More concretely, using the most preferable specification, i.e., column (4), if a firm implements wage cuts, it will reduce the probability of layoffs by 0.172 . In other words, this may suggest that wage cuts and layoffs are in a mutually alternative relationship, and the result of the estimated causal relation suggests that the wage cut functions as an effective measure to avert layoffs.

In this study, we obtained a result exactly consistent with the argument of downward rigidity of wages, in which wage cuts reduce layoffs and, hence, unemployment. That

Table 3 Layoff regression (probit and IV-probit)

\begin{tabular}{|c|c|c|c|c|}
\hline Dependent variable: layoff = 1 & (1) & (2) & (3) & (4) \\
\hline Method & Probit & Probit & IV-probit & IV-probit \\
\hline \multirow[t]{2}{*}{ Wage cut $=1$} & 0.466 & 0.547 & -0.364 & -0.172 \\
\hline & $(0.095)$ & $(0.104)$ & $(0.059)$ & $(0.038)$ \\
\hline \multirow[t]{2}{*}{ In(capital size (million yen))/100 } & -0.343 & -0.381 & -0.551 & -0.796 \\
\hline & $(0.111)$ & $(0.113)$ & $(0.479)$ & $(0.376)$ \\
\hline \multirow[t]{2}{*}{ Firm age/1000 } & -0.255 & -0.303 & -0.275 & -0.443 \\
\hline & $(0.181)$ & $(0.179)$ & $(0.499)$ & $(0.486)$ \\
\hline \multirow[t]{2}{*}{ Limitation for voluntary retirement } & - & -0.198 & - & -0.363 \\
\hline & & $(0.038)$ & & $(0.337)$ \\
\hline \multicolumn{5}{|l|}{ Reason for downsizing dummies } \\
\hline \multirow{2}{*}{$\begin{array}{l}\text { To cope with critical management adversity } \\
\text { expected in the future }\end{array}$} & - & 0.021 & - & 0.052 \\
\hline & & $(0.010)$ & & $(0.027)$ \\
\hline \multirow{2}{*}{$\begin{array}{l}\text { To cope with a present, temporary profit } \\
\text { reduction }\end{array}$} & - & 0.038 & - & 0.064 \\
\hline & & $(0.013)$ & & $(0.042)$ \\
\hline \multirow{2}{*}{$\begin{array}{l}\text { To improve earnings by focusing on the } \\
\text { company's specialty }\end{array}$} & - & 0.002 & - & 0.021 \\
\hline & & $(0.020)$ & & $(0.055)$ \\
\hline \multirow[t]{2}{*}{ No response } & - & 0.036 & - & 0.187 \\
\hline & & $(0.027)$ & & $(0.199)$ \\
\hline Foundation year dummies & Yes & Yes & Yes & Yes \\
\hline Pseudo- $R^{2} /$ log likelihood & 0.272 & 0.303 & 1108.786 & 1119.368 \\
\hline$N$ & 1491 & 1491 & 1491 & 1491 \\
\hline \multicolumn{5}{|c|}{ Tests of overidentifying restrictions ( $\mathbf{H}_{0}$ : all IVs exogenous) } \\
\hline$\chi^{2}$ & - & - & 0.292 & 0.131 \\
\hline$P$-value & - & - & 0.589 & 0.718 \\
\hline
\end{tabular}

Note: Standard errors clustered at an industry level are reported in parentheses. Marginal effects evaluated at the mean of the covariates are reported. One question concerns the application criteria and the limitations regarding eligibility for voluntary retirement and the early retirement incentive plan. "Limitation for Voluntary Retirement" takes the value of 1 if the firm circled at least one of the following categories: age, tenure, position, job type, and department. The degree of introduction of a performance-based payment system is used as an IV for wage cut. The reference group for the reason for downsizing dummies is "To Cope with Present Critical Management Adversity." For firms that had not yet laid off workers, the question about the reason for downsizing asks about the main possible reason for the potential downsizing 
said, the study successfully explained, from the viewpoint of behavioral economics, the mechanism by which wage cuts reduce layoffs.

For other coefficients, the greater the capital size and the longer the history of the business, the less likely that layoffs will be implemented, which sounds like a reasonable result. The reason for downsizing dummies is insignificant overall.

Concerning the exogeneity of the instrument variable, the introduction of a performance-based payment system in the past is allowed to correlate with layoffs only through wage cuts. In the first place, it is unlikely that whether a performance-based payment system was previously introduced or not directly correlates with factors in the error term that determine the current layoff decision, after each firm's current situation and original characteristics, such as capital size, firm age, and rules of voluntary retirement, are controlled for. In addition to this, we also implemented over-identifying restrictions tests using the two IVs and confirmed that all the IVs are statistically exogenous as shown in Table 3. ${ }^{7}$ We also tested many specifications but, after trying many specifications, found that the negative coefficient of wage cuts with statistical significance does not change at all in the IV regressions. Thus, we believe that our estimates are very robust. It is true that the adoption of a performance-based payment system was originally an endogenous choice, but it is not surprising that we passed the test of over-identifying restrictions: We utilized the result of past decision on the adoption of a performance-based payment system and found that it is unlikely that past choice influences factors that determine the current layoff decision after controlling for various firms' current characteristics as well as those fixed over time.

\section{Conclusion}

In this paper, we have analyzed the optimal combination of wage cuts and layoffs from the viewpoint of behavioral economics, using sufficiently wide valuable data in Japan. By conducting an empirical analysis using the instrumental variable method, we cleared the simultaneous problem and estimated the impact of wage cuts on implementation of layoffs.

The theoretical model and first-stage regression reveal that the more heavily a firm relies on a performance-based payment system, the less likely it is to impose wage cuts, and the parameter of wage piece rate employed in the theoretical model can be partially captured by the presence or absence of a performance-based payment system. In the IV regression, the status of a performance-based payment system, based on the firm's past decision and assured to be exogenous, is utilized as an IV for wage cuts, and the secondstage regression showed that the imposition of wage cuts significantly reduced layoffs.

This result has important implications for employment practices: As an unexpected side effect of the haphazard use of a performance-based payment system, layoffs will increase because firms become less likely to implement wage cuts. This may lead to a high unemployment rate.

\section{Endnotes}

${ }^{1}$ Martins (2009) finds that firms that gain flexibility in terms of dismissals see their performance improves considerably. However, he finds only moderate evidence of increases in worker flows and hirings and no evidence that the higher levels of firm performance then lead to higher wages. 
${ }^{2}$ Note that in this model, we consider a situation where a firm collects a certain amount of money from wage cuts and/or layoffs, taking the existing wage structure as given. Thus, the source of the saved money $(d)$, i.e. whether they come from a fixed pay or piece rate, is not of interest here. For these reasons, we assume that the wage cuts take the form of a subtraction from the total payment, and endogenizing the fixed pay and piece rate lies outside the scope of this study since we are interested solely in the amount of money saved from the total wages regardless of its source.

${ }^{3}$ This model setting is based on Bewley's (1999) finding that workers' morale does not increase with wage increase, while it can be damaged by pay reductions.

${ }^{4}$ In most economic models, firms lay workers off randomly or based on seniority. For example, Baily (1977) and Macleod et al. (1994) presented models wherein firms lay off workers randomly, while Grossman (1983) and Reagan (1992) assumed seniority-based layoffs. Nosal (1990), Strand (1991), and Strand (1992) considered both types of layoffs. Laing (1994) and Gibbons and Katz (1991) proposed signaling models wherein firms may choose to lay off workers according to their observed abilities. Ioannides and Pissarides (1983) presented a model in which a firm decides to lay off a worker based on information about an external offer to the worker. In Shapiro and Stiglitz (1984), the dismissal rule is given exogenously, and workers caught shirking are fired. Sparks (1986) and Yokoyama (2014) further developed the rule of Shapiro and Stiglitz (1984) by making workers' level of effort and criterion for dismissal endogenous. In Sparks' model, it is assumed that workers who provide effort equal to or above the minimum standard are never dismissed. Yokoyama (2014) made the dismissal rule in Sparks (1986) contingent on the output price.

${ }^{5}$ This condition corresponds to the instrument relevance assumption in the empirical section, which assures a sufficient correlation between the endogenous variable, i.e., wage cuts, and the instrumental variable, i.e., the status of a performance-based payment system.

${ }^{6}$ The survey also asked about application criteria for and limitations in eligibility for voluntary retirement and early retirement incentive plans. For example, the categories of age, length of service, position, job type, and department are potential factors in avoiding voluntary retirement; thus, these factors can also be considered to affect layoff decisions.

${ }^{7}$ In addition to the fact that each firm has implemented a performance-based payment system, information about the future plan for the payment system can also be obtained from the survey. Thus, a dummy variable that takes the value of 1 if the firm is planning to introduce a performance-based payment system is also available as another IV.

\section{Acknowledgements}

This research is supported by the Grant-in-Aid for Scientific Research (\#25885033, PI: Izumi Yokoyama). This paper was presented at the Japanese Economic Association on October 11, 2015. We are thankful that Masaru Sasaki kindly agreed to be a discussant for our presentation at the Japanese Economic Association and gave us many constructive comments. We wish to thank Isao Ohashi, Motohiro Sato, and Tomoharu Mori, who provided invaluable advice. Finally, we want to thank the Japan Institute for Labor Policy and Training (known then as the "Japan Institute of Labor") for providing the data from the "Survey on Business Restructuring and Employment, 2002." I would also like to thank the anonymous referee and the editor for the helpful comments.

Responsible editor: Juan Jimeno

Authors' information

Izumi Yokoyama is an assistant professor in the Graduate School of Economics, Hitotsubashi University.

Takuya Obara is a Ph.D. student in the Graduate School of Economics, Hitotsubashi University.

Competing interests

The IZA Journal of Labor Policy is committed to the IZA Guiding Principles of Research Integrity. The authors declare that they have observed these principles. 


\section{Publisher's Note}

Springer Nature remains neutral with regard to jurisdictional claims in published maps and institutional affiliations.

Received: 14 July 2017 Accepted: 22 November 2017

Published online: 06 December 2017

\section{References}

Akerlof G, Yellen J (1988) Fairness and unemployment. Am Econ Rev 78(2):44-9

Akerlof G, Yellen J (1990) The fair wage-effort hypothesis and unemployment. Q J Econ 105(2):255-83

Akerlof GA (1982) Labor contracts as partial gift exchange. Q J Econ 97(4):543-69

Azariadis C (1975) Implicit contracts and underemployment equilibria. J Polit Econ 83(6):1183-202

Baily MN (1974) Wages and employment under uncertain demand. Rev Econ Stud 41(1):37-50

Baily MN (1977) On the theory of layoffs and unemployment. Econometrica 45(5):1043-63

Bewley TF (1999) Why wages do not fall during a recession. Harvard University Press, Cambridge

Frey BS (1997) Not just for the money: an economic theory of personal motivation. Edward Elgar Publishing, Cheltenham

Frey BS, Jegen R (2001) Motivation crowding theory. J Econ Surv 15(5):589-611

Gibbons R, Katz LF (1991) Layoffs and lemons. J Labor Econ 9(4):351-80

Gneezy U, List JA (2006) Putting behavioral economics to work: testing for gift exchange in labor markets using field experiments. Econometrica 74(5):1365-84

Gordon DF (1974) A neo-classical theory of keynesian unemployment. Econ Inq 12(4):431-59

Grossman GM (1983) Union wages, temporary layoffs, and seniority. Am Econ Rev 73(3):277-90

Hennig-Schmidt H, Sadrieh A, Rockenbach B (2010) In search of workers' real effort reciprocity — a field and a laboratory experiment. J Eur Econ Assoc 8(4):817-37

loannides YM, Pissarides CA (1983) Wages and employment with firm-specific seniority. Bell J Econ 14(2):573-80

Kawaguchi D, Ohtake F (2007) Testing the morale theory of nominal wage rigidity. Ind Labor Relat Rev 61(1):59-74

Kube S, Maréchal MA, Puppe C (2013) Do wage cuts damage work morale? Evidence from a natural field experiment.

J Eur Econ Assoc 11(4):853-70

Laing D (1994) Involuntary layoffs in a model with asymmetric information concerning worker ability. Rev Econ Stud 61(2):375-92

Lindbeck A, Snower D (1988) Cooperation, harassment, and involuntary unemployment: an insider-outsider approach. Am Econ Rev 78(1):167-88

Macleod WB, Malcomson JM, Gomme P (1994) Labor turnover and the natural rate of unemployment: efficiency wage vs frictional unemployment. J Labor Econ 12(2):276-315

Martins PS (2009) Dismissals for cause: the difference that just eight paragraphs can make. J Labor Econ 27(2):257-79

Nosal E (1990) Incomplete insurance contracts and seniority layoff rules. Economica 57(228):423-38

Reagan PB (1992) On-the-job training, layoff by inverse seniority, and the incidence of unemployment. J Econ Bus 44(4):317-24

Shapiro C, Stiglitz JE (1984) Equilibrium unemployment as a worker discipline device. Am Econ Rev 74(2):433-44

Sparks R (1986) A model of involuntary unemployment and wage rigidity: worker incentives and the threat of dismissal. J Labor Econ 4(4):560-81

Strand J (1991) Unemployment and wages under worker moral hazard with firm-specific cycles. Int Econ Rev 32(2):601-12 Strand J (1992) Business cycles with worker moral hazard. Eur Econ Rev 36(6):1291-303

Yokoyama I (2014) Why do wages become more rigid during a recession than during a boom? IZA J Labor Econ 3(6). https://doi.org/10.1186/2193-8997-3-6

\section{Submit your manuscript to a SpringerOpen ${ }^{\circ}$ journal and benefit from:}

- Convenient online submission

- Rigorous peer review

- Open access: articles freely available online

- High visibility within the field

- Retaining the copyright to your article

Submit your next manuscript at $\boldsymbol{\triangleright}$ springeropen.com 